\title{
Screening and Treating Malaria in Pregnancy by Community Health Workers in Benin, Burkina Faso and Gambia: Profiles, Perceptions and Time Commitments
}

\section{Laetitia Duval}

Centre d'Economie de la Sorbonne, University Paris 1 Panthéon-Sorbonne, Paris

\section{Elisa Sicuri}

MRC Centre for Global Infectious Disease Analysis, School of Public Health, Imperial College London,

\section{Susana Scott}

4Infectious Disease Epidemiology Department, London School of Hygiene \& Tropical Medicine, London

Maminata Traoré

Infectious Disease Epidemiology Department, London School of Hygiene \& Tropical Medicine, London

Halidou Tinto

Institut de Recherche en Sciences de la Santé - Clinical Research Unit of Nanoro, Nanoro, Burkina Faso

\section{Koen Peeters Grietens}

Medical Anthropology Unit, Department of Public Health, Institute of Tropical Medicine, Antwerp,

\section{Umberto d'Alessando}

Medical Research Council Unit The Gambia at London School of Tropical Medicine and Hygiene, Fajara

\section{Alain Nahum}

Centre de Recherches Entomologiques de Cotonou,

\section{Henk Schallig}

Academic Medical Centre, Department of Medical Microbiology, Parasitology Unit,

\section{Petra Mens}

9Academic Medical Centre, Department of Medical Microbiology, Parasitology Unit,

\section{Lesong Conteh ( $\square$ I.conteh@lse.ac.uk)}

The London School of Economics and Political Science https://orcid.org/0000-0002-0719-3672

\section{Research}

Keywords: Malaria, pregnancy, community health worker, time and motion, Sub-Saharan Africa, Benin, Burkina Faso, Gambia

Posted Date: July 8th, 2020 
DOI: https://doi.org/10.21203/rs.3.rs-40535/v1

License: (c) (1) This work is licensed under a Creative Commons Attribution 4.0 International License. Read Full License 


\section{Abstract \\ Background}

To date, there have been few studies on the roles and challenges that community health workers (CHWs) face when encouraging pregnant women to attend health facilities and provide community-based interventions including scheduled screening and treatment (CSST) for malaria. This study investigates the characteristics, daily activities and time commitments of CHWs tasked with delivering CSST as part of a cluster-randomized controlled trial in Benin, Burkina Faso and Gambia.

\section{Methods}

$45 \mathrm{CHWs}$ were interviewed and observed in three rural settings in West Africa, both during and outside the malaria transmission seasons.

\section{Results}

CHWs in all three settings were predominantly male, over 30 years old and relied on farming for income. Most had completed secondary school in Benin (77\%) but not in Burkina Faso (33\%) or The Gambia (27\%). In Benin, most had been in post between 5 to 10 years; in Burkina Faso and The Gambia the majority had been $\mathrm{CHWs}$ for over 10 years. CHWs in Burkina Faso received the highest monthly financial reward for taking part in the trial (US\$40), next was Benin (US\$22.60) and finally Gambian CHWs received US\$11. While the CHWs welcomed the increased training, knowledge and skills they acquired on screening and treating malaria in pregnancy afforded by the trial, they also expressed concern about the transportation challenges of successful community-based interventions in remote areas. CHW duties were a bigger time commitment in Burkina Faso than Benin. The time committed to CHW activities (trial and non-trial) was longer during than outside the malaria transmission season.

\section{Conclusions}

This study highlights the importance of taking into account the variety of existing $\mathrm{CHW}$ responsibilities when designing and implementing evidence-based policy to address malaria in pregnancy. The findings emphasise the need to consider both financial and non-financial factors likely to impact the scale-up and sustainability of interventions beyond trial conditions.

\section{Background}

Malaria in pregnancy continues to be a major public health problem in sub-Saharan Africa. Pregnant women have a higher risk of malaria than other adults with risks for their fetus, the newborn child and pregnant women themselves [1-5]. The World Health Organization (WHO) advocates prompt and 
effective management of clinical cases, long-lasting insecticidal nets and intermittent preventive treatment during pregnancy with sulfadoxine-pyrimethamine (IPTp-SP). WHO recommends three or more does of IPTp-SP are given at least one month apart from the second trimester at routine antenatal care visits [6]. Among 36 African countries that reported on IPTp-SP coverage levels in 2018, only an estimated $31 \%$ of eligible pregnant women received the recommended three or more doses, an improvement on 2017 coverage levels of $22 \%$ [7].

A range of geographic, economic, health system, social and cultural factors contribute to the low use of antenatal clinics by pregnant women. These factors include, among others, distance and poor road infrastructure, low level of education, poverty, limited access to information and traditional values [8-15]. Even for those women who use antenatal care services at least once during their pregnancy, $18 \%$ do not receive any IPTp [7]. There is, therefore, a need to explore alternative ways of increasing IPTp-SP coverage. In a bid to overcome some of these barriers to access, a cluster-randomised controlled trial was undertaken in Benin, Burkina Faso and The Gambia to evaluate if a community-based scheduled screen and treat (CSST) strategy targeted at pregnant women would improve maternal and infant health. Specifically, community health workers (CHWs) were asked to encourage pregnant women to attend health facilities for IPTp-SP at the recommended times, and in between visits, to screen for malaria infection and treat, if positive, pregnant women $[16,17]$.

The increased interest in bringing health services nearer to the communities they serve has led to more interventions delivered via CHWs [18-22]. Those targeting malaria have also looked to $\mathrm{CHWs}$ as possible routes to reduce the disease burden [23-29]. Questions remain about their capacity to absorb extra activities, both in terms of their available time, training, supervision and personal preferences.

The results of the trial this study was aligned to showed that adding CSST by CHWs to the standard IPTpSP at ANC did not reduce the risk of placental malaria or peripheral malaria infection at delivery [17]. While the trial may not have shown an effect on its primary outcome, it did offer a unique multi-country opportunity to explore the wider roles and responsibilities of $\mathrm{CHWs}$ and better understand their capacity to add a potential new malaria strategy to their existing work schedule. We assess the profiles and time commitments of the CHWs in the three rural trial settings in relation to (i) screening and treating malaria in pregnancy as part of the intervention and (ii) existing, routine malaria treatment more generally. The study also focuses on understanding how the CHWs perceived the benefits (both financial and nonfinancial) and costs of delivery for the CSST intervention. Even accounting for the possibilities of a trial effect [30,31], this explorative study allows us to follow all CHWs recruited to deliver CCST in three West African countries in a bid to explore in more detail issues around absorption capacity and the wider context in which they already operate [27].

\section{Methods}

\section{Study setting and population}


This study was part of a multi-centre cluster-randomized controlled trial in Benin, Burkina Faso and The Gambia designed to develop an extension strategy to the communities in rural areas in addition to the standard IPTp-SP delivered through health facilities, called "Community Based Scheduled Screening and Treatment of Malaria in Pregnancy for Improved Maternal and Infant Health" (COSMIC study)[17]. In Benin, the study was implemented in the Atlantic Region in the southern part of the country, in the GloDjigbé, Zinvié and Zè district communities. Malaria transmission occurs during two rainy seasons (AprilJuly and October-November). In Burkina Faso, the study was implemented in the middle of the country, in the Nanoro Health district, with seasonal malaria transmission between June and December. In The Gambia, the study was implemented in the eastern part of the country, in the south bank of the Upper River Region, Basse Health district, with seasonal malaria transmission occurring between July and December.

IPTp-SP was adopted as a national policy in 2002 in The Gambia, and in 2005 in both Benin and Burkina Faso [32]. In all three countries, the policy was to give IPTp-SP twice during pregnancy starting from the second trimester when they attend the health facility. However in 2014, WHO provided the additional recommendation to administer IPTp-SP at each scheduled ANC visit, starting as early as possible in the second trimester and provided the doses are given at least one month apart [33]. Such recommendation was adopted by Burkina Faso during the study period. For both Benin and The Gambia, the policy remained only two doses during the trial. CHWs were already managing malaria cases in the framework of community case management of malaria (CCMm) in the three countries but the policy was at various stages of implementation [16]. In Benin, CCMm was part of the National Malaria Policy but needed to be scaled up nationwide [34]. In Burkina Faso, CCMm had been implemented and managed by nongovernment organisations under the supervision of the National Malaria Control Program [35]. In The Gambia, the National Malaria Control Program was planning to introduce nationwide CCMm supported by Rapid Diagnostic Tests (RDT) [36].

\section{Data collection}

Data collection tools, both in English and French, were developed and designed in two parts with mostly quantitative response options and a small number of qualitative ones. The data collection tools were piloted over several weeks in each setting and refined after fieldworkers and CHWs feedback.

The first part consisted of a mix of both open and close-ended questions designed to understand the general characteristics of the CHWs. The questionnaire sought the socio-economic characteristics of the $\mathrm{CHW}$ such as sex, age, level of education and their main source of income. The questionnaire also explored the $\mathrm{CHWs}$ selection, their financial and non-financial incentives and their perceptions of the benefits/costs of being involved in the intervention.

The second part of the data collection was a time and motion analysis carried out in 2015. This was during the second year of the trial to allow CHWs to become familiar with CSST and possibly reflect on a more efficient approach to the intervention. Experienced data collectors observed the CHWs on 5 different occasions, both during (3 occasions) and outside of the malaria transmission season (2 occasions) 
using a stopwatch to record each activity and the time spent on major activities and tasks. The total hours CHWs spent on intervention related activities and non-intervention related activities, both inside and outside the malaria transmission season, were recorded in all three countries.

Prior to the clinical trial starting, community sensitization and involvement of village leaders was carried out at each study site. In addition to the CHWs consenting to take part in the wider trial, specific ethical clearance and informed consent for the interviews was sought via the relevant in-country ethics committees and Imperial College London. Data collectors administered questionnaires in the native language of the CHWs.

\section{Data management and analysis}

All data were collected through standardized questionnaires in the three countries, double entered into a specially designed database and verified. The free text from open ended questions was organised in an excel template with themes associated with preferences grouped together. All questionnaires were labeled with the $\mathrm{CHW}$ unique identity number and date of collection. Confidentiality of information collected was ensured by anonymizing data collection forms and storing data on password-protected computers. Financial incentives were reported in local currencies. Costs were then converted in US dollars using the average exchange rate over the January-December 2015 period [37]. Analysis was done using Microsoft Excel and Stata software (StataCorpLP, http://www.stata.com).

\section{Results}

\section{CHW Characteristics}

The large majority of CHWs were male, with a small percentage of females in Benin (13\%), Burkina Faso (20\%) and none in The Gambia (Table 1). Most CHWs were above 30 years of age, with Gambian CHWs slightly older than in the other two countries. CHW in Benin received more formal education; $73 \%$ of them had completed secondary education while in Burkina Faso and The Gambia such proportion was 33\% and $27 \%$, respectively. In The Gambia, $60 \%$ of the CHWs had attended a Koranic schooling, and $27 \%$ were unable to read and write in English. In Benin, all the CHWs could read and write in French while in Burkina Faso $80 \%$ could do so. The main source of income was farming for the whole sample of CHWs (Table 1 ). All CHWs in Benin and The Gambia had been selected by the community while in Burkina Faso there were $20 \%$ selected by the local health center. The duration in post varied by country although the large majority had served for more than 5 years. In Burkina Faso and The Gambia, more than half had served more than 10 years (Table 1$)$. 
Table 1

Descriptive statistics of the sample General characteristics of the CHWs by country (\%)

\begin{tabular}{|c|c|c|c|}
\hline Variables & Benin & Burkina Faso & The Gambia \\
\hline Females & 13 & 20 & 0 \\
\hline Age $20-29$ & 20 & 7 & 7 \\
\hline $30-39$ & 47 & 40 & 27 \\
\hline $40-49$ & 20 & 20 & 33 \\
\hline $50+$ & 13 & 33 & 33 \\
\hline Main education type None & - & - & - \\
\hline Koranic school & - & - & 60 \\
\hline Western school & 100 & 100 & 40 \\
\hline Education level Primary & 27 & 67 & 67 \\
\hline Secondary & 73 & 33 & 27 \\
\hline Higher education & - & - & 6 \\
\hline Main source of income Farming & 53 & 93 & 87 \\
\hline Small business & 20 & - & 13 \\
\hline Tailor & 7 & - & - \\
\hline Civil servant & - & - & - \\
\hline $\mathrm{CHW}$ & - & - & - \\
\hline Other & 20 & 7 & - \\
\hline Selection process By community & 100 & 80 & 100 \\
\hline By health center & - & 20 & - \\
\hline Duration in post Less than 1 year & - & - & 7 \\
\hline Between 1 and 5 years & 33 & 7 & 20 \\
\hline Between 5 and 10 years & 67 & 40 & 20 \\
\hline More than 10 years & - & 53 & 53 \\
\hline Number of observations & 15 & 15 & 15 \\
\hline
\end{tabular}




\section{Financial}

There were differences between the three countries in terms of financial incentives to $\mathrm{CHW}$ for being part of the trial. Table 2 presents the average reported financial incentives per month CHWs earned for delivering the intervention under trial conditions compared to the incentives received for all other non-trial CHWs activities. In Burkina Faso, $\mathrm{CHWs}$ received the highest financial incentives for their contribution to the trial (about 40 US\$ per month) than those in Benin (22.60 US\$) and The Gambia (11 US\$). The difference in trial incentives by country is not reflected by incentives received for non-trial activities as $\mathrm{CHW}$ in Benin were the best paid and received the highest amount of money per month (100.90 US\$). Both in Burkina Faso and in The Gambia, the financial incentives for the trial were much higher than those for non-trial activities, with the larger proportion difference in The Gambia (> 6-fold higher), and then in Burkina Faso (about 2-fold higher). The reasons and implications for this are discussed later.

Table 2

CHW financial incentives per month (US\$ 2015)

\begin{tabular}{|llll|}
\hline Variables & Benin & Burkina Faso & Gambia \\
\hline Intervention financial incentives & 22.60 & 40.40 & 11 \\
\hline Other CHW activities' financial incentives & 78.30 & 19.80 & 1.70 \\
\hline Total financial incentives & 100.90 & 60.20 & 12.70 \\
\hline Number of observations & 15 & 15 & 15 \\
\hline
\end{tabular}

\section{Non-financial}

There was general agreement across all the $\mathrm{CHWs}$ about the non-financial benefits of delivering the intervention. All mentioned the free phone communication (Table 3). In Benin, they also mentioned a free t-shirt and a free backpack. Benefits were not only material. CHWs in all countries explained their raised status in the village and the community recognition. They also highlighted the training on malaria that the intervention offered to them, particularly how to collect a blood spot on filter paper and how to screen pregnant women with RDTs. They welcomed having a better understanding of malaria in pregnancy and how they were better able to explain to pregnant women the importance of attending the ANC visits at health facilities. 
Table 3

Non-financial benefits for being in the intervention

\begin{tabular}{|lll|}
\hline Benin & Burkina Faso & Gambia \\
\hline - Free phone & - Free phone communication & - Free phone \\
communication & - Better understanding of pregnant women & $\begin{array}{l}\text { commication } \\
\text { - Faised status in the } \\
\text { village }\end{array}$ \\
- Free backpack & - Raised status in the village & \\
- Training on malaria & - & thank you \\
- Raised status in the & - Community recognition & \\
village & - More knowledge on malaria & \\
- Community & - Acquisition of skills & \\
recognition & & \\
\hline
\end{tabular}

\section{Time commitment to trial}

$\mathrm{CHWs}$ in Burkina Faso reported the highest amount of time spent on screening and treating malaria during malaria season (3.7 days per week) and outside (2.1 days per week) malaria season, followed by The Gambia (3.6 days per week during and 1.6 days per week outside malaria season). In Benin, CHWs on average worked 3.4 days in the malaria season and 1.6 days per week on intervention activities outside malaria season (Table 4).

Table 4

Mean CHW days spent on COSMIC trial activities per week

\begin{tabular}{|llll|}
\hline & Benin & Burkina Faso & Gambia \\
\hline Malaria season & 3.4 days & 3.7 days & 3.6 days \\
\hline Outside malaria season & 1.6 days & 2.1 days & 1.6 days \\
\hline Number of CHWs observed & 15 & 15 & 15 \\
\hline $\begin{array}{l}\text { Notes: Minimum duration CHWs observed is } 3 \text { days for malaria season and 1 day outside malaria } \\
\text { season in the three countries. Maximum duration is 5 days for malaria season and 3 days outside } \\
\text { malaria season in the three countries. }\end{array}$ & & \\
\hline
\end{tabular}

\section{Time and Motion}

Each day, CHW spent a certain number of hours per day for health-related activities, including trial-related activities (Table 5). The CHW in Burkina Faso dedicated the largest amount of time to health-related activities, both during outside the malaria transmission season, with trial-related activities representing between $23 \%$ and $39 \%$ of the total. In the other two countries, trial-related activities represented all activities (The Gambia) or a substantial proportion (Benin). Such differences, and specifically the relatively little time spent on trial-related activities in Burkina Faso, can be explained by other activities 
undertaken by $\mathrm{CHW}$ such as immunization campaigns, malnutrition campaigns as well as cleaning of the health center.

Table 5

Mean CHW hours/day spent on COSMIC and other non-COSMIC activities per day (T\&M)

\begin{tabular}{|llll|}
\hline & Benin & Burkina Faso & Gambia \\
\hline Malaria season & & & \\
\hline COSMIC & 1.3 & 1.4 & $\mathrm{NA}$ \\
\hline Other & 1.1 & 4.6 & \\
\hline subtotal & 2.4 & 6.0 & 2.5 \\
\hline Outside malaria season & & & $\mathrm{NA}$ \\
\hline COSMIC & 1.2 & 1.6 & 15 \\
\hline Other & 0.7 & 2.5 & \\
\hline $\begin{array}{l}\text { subtotal } \\
\text { Number of CHWs observed }\end{array}$ & 1.9 & 4.1 & 15 \\
\hline $\begin{array}{l}\text { Notes: Each of the 15 CHWs, in each country to be observed on } 5 \text { separate occasions. In malaria } \\
\text { season on 3 occasions/ outside malaria season: } 2 \text { occasions. Missing observations: } 4 \text { occasions } \\
\text { missing during malaria season in Burkina Faso; } 3 \text { missing observations during malaria season and } 1 \\
\text { missing observation outside malaria season in Benin. NA: not available. }\end{array}$ \\
\hline
\end{tabular}

\section{Challenges and solutions}

When the CHWs were asked about the challenges specifically related to the trial intervention, i.e. screening and treating malaria, they mentioned difficulties with transport. They also explained the difficulty of reaching pregnant women for home visits and their frustrations of not finding them at home when they had planned an appointment. They also mentioned the financial incentives were too low in The Gambia and Benin. In terms of potential solutions provided, they mentioned the need to provide a motorbike or bicycle to facilitate their daily activities, especially during the rainy season. They also suggested the importance of community sensitization and the acquisition of skills on how to manage pregnant women.

\section{Discussion}

CHWs in all three settings were predominantly male, over 30 years old and relied on farming for income. In Benin most had been to secondary school, but not in Burkina Faso or The Gambia. In Benin, most were in post between 5 and 10 years, in Burkina Faso and The Gambia the majority had been CHWs for over 10 years. The most notable differences between settings were in terms of their incentives and time commitments to $\mathrm{CHW}$ duties. In Burkina Faso, CHWs were observed spending the most time on their 
activities both in terms of weekly and daily commitments. They also received the highest financial incentives paid to $\mathrm{CHWs}$ delivering the COSMIC intervention. Their incentive was aligned on that paid officially by the government to CHWs of approximately 40 US\$ per month. The level of incentives for The Gambia were discussed with community leaders to ensure they were in line with incentives given for previous similar works in other MRC projects and also in line with salaries in The Gambia in general.

No clear pattern emerged of whether CHWs were substituting their time between COSMIC and nonCOSMIC activities. Indeed, it appears that while the time to undertake CSST remained similar during and outside of the malaria season, it was time spent on other activities that showed the most variation. When given an opportunity to report challenges, the time taken to do COSMIC related activities was not mentioned. Our findings echo other studies that found CHWs increasingly involved in CSST programmes face significant challenges $[24,38]$. The results vary depending on the setting. In The Gambia and Benin for instance, the $\mathrm{CHWs}$ mentioned challenges related to their low remuneration. This corroborates several studies regarding remuneration as a source of $\mathrm{CHWs}^{\prime}$ dissatisfaction $[24,39,40]$. All $\mathrm{CHWs}$ in the three countries emphasized transport difficulties, including movements between villages, especially during the rainy season; a barrier also noted in Senegal [41]. These frustrations may be mitigated both by better transportation and the use of mobile phones to remind pregnant women about their IPTp-SP visits [42, 43]. However, CHWs stayed motivated by the social recognition that they received while doing their work in the community.

While acknowledging the small sample size, our findings offer a multi-country look at the CHW characteristics and time commitment related to malaria screening and treating activities. These findings add to the growing evidence on the impact new interventions place on CHWs workload, both positive and negative [44-48]. We highlight the importance of taking into account the local health system realities when planning and sustaining new CHW led interventions, as suggested in several studies [18, 24, 27].

This study has its limitations. Although the time and motion approach is considered the gold standard for measuring health workers' time use, it is labor-intensive and can only be done with a small number of participants [49-51]. As with all studies of this type, there was a risk of the Hawthorne effect, as while being observed, it is possible that the CHWs changed their behaviors $[52,53]$. For example, CHWs may have wanted to demonstrate their challenging working conditions and therefore chosen, on the observation days, to visit pregnant women who lived very far from the health facility. In addition, contrary to other studies [24,41], the CHWs in this study did not mention the lack of training or lack of supplies as challenges of their work. This is likely due to the trial context and because the intervention provided high levels of training, supervision and ensured drug supplies over the trial period.

The COSMIC trial results showed that adding community-based scheduled screening and treatment by $\mathrm{CHWs}$ to the standard IPTp-SP at ANC did not reduce the risk of placental malaria or peripheral malaria infection at delivery. The COSMIC trial did, however, support previous evidence that $\mathrm{CHWs}$ can both correctly use RDTs and adhere to test results and treatment guidelines [54,55], increase ANC attendance, particularly in early pregnancy (in Burkina Faso), identify and treat infections between scheduled ANC 
visits, and encourage women to adhere to a full treatment course. All these aspects point to the potential of $\mathrm{CHWs}$ in curbing malaria.

\section{Conclusion}

Despite expanding international commitment to $\mathrm{CHWs}$ deployment in low-income countries, not enough is known about their socio-economic characteristics and how they perceive, organise and structure their time. This study aimed to better understand CHWs in the context of screening and treating malaria in pregnancy in Benin, Burkina Faso and The Gambia. Any intervention aimed at adding community-based scheduled screening and treatment by $\mathrm{CHWs}$ may need to address challenges $\mathrm{CHWs}$ face in terms of remuneration and transport. Our findings support the need to understand individual $\mathrm{CHW}$ characteristics, roles and responsibilities. Moreover, the introduction of any new intervention that draws upon CHWs must appreciate the wider health system and community characteristics that will support the introduction and sustained delivery of $\mathrm{CHW}$ led interventions.

\section{Abbreviations}

CCMm

community case management of malaria

CSST

community-scheduled screening and treatment

$\mathrm{CHW}$

community health worker

IPTp-SP

intermittent preventive treatment during pregnancy with sulfadoxine-pyrimethamine

RDT

rapid diagnostic test

T\&M

time and motion

WHO

World Health Organization

\section{Declarations}

\section{Ethics approval and consent to participate}

Ethical approvals by the Gambia Government/MRC laboratories Joint Ethics Committee, the Institutional Ethics Committee of Centre Muraz in Burkina Faso, the Comité National d'Ethique pour la Recherche en Santé in Benin and Imperial College London in United Kingdom were obtained. Informed written consent were obtained from all participants. 


\section{Consent for publication}

\section{Availability of data and material}

The datasets used and/or analysed during the current study are available from the corresponding author on reasonable request.

\section{Competing interests}

The authors declare that no competing interests exist.

\section{Funding}

The research was funded by the European Union Seventh Framework Programme (FP7/2002-2016) under grant agreement $n^{\circ} 305662$ - (Project: Community-based scheduled screening and treatment of malaria in pregnancy for improved maternal and infant health: a cluster-randomized trial 'COSMIC'). The funder had no role in study design, data collection and analysis, decision to publish, or preparation of the manuscript. We acknowledge joint funding from the UK Medical Research Council and Department for International Development. MR/R015600/1

\section{Authors' contributions}

LD and LC conceived and designed the study. LD and LC drafted and wrote the manuscript. LD and ES provided the statistical input to the study. HS, PM, HT, AN, KPG, LC, MB, AN and UdA designed the overall COSMIC project of which this economic study was part of. PM and HS were responsible for the overall coordination of the project. SS, MT, HT and AN helped facilitate the incountry data collection. All authors read and approved the final manuscript.

\section{Acknowledgements}

We are grateful to the community health workers who participated in the study. We would like to thank the community members for their cooperation and Bunja Daabo, Anicet Gbaguidi, Regina Segda who collected the data.

\section{References}

1. Steketee RW, Nahlen BL, Parise ME, Menendez C. The burden of malaria in pregnancy in malariaendemic areas. Am J Trop Med Hyg. 2001;64:28-35.

2. Desai M, ter Kuile FO, Nosten F, McGready R, Asamoa K, Brabin B, Newman RD. Epidemiology and burden of malaria in pregnancy. Lancet Infectious Diseases. 2007;7:93-104. 
3. Bardaji A, Sigauque B, Sanz S, Maixenchs M, Ordi J, Aponte JJ, Mabunda S, Alonso PL, Menendez C. Impact of Malaria at the End of Pregnancy on Infant Mortality and Morbidity. J Infect Dis. 2011;203:691-9.

4. Rogerson SJ, Desai M, Mayor A, Sicuri E, Taylor SM, van Eijk AM. Burden, pathology, and costs of malaria in pregnancy: new developments for an old problem. Lancet Infect Dis. 2018;18:e107-18.

5. Hartman TK, Rogerson SJ, Fischer PR. The impact of maternal malaria on newborns. Ann Trop Paediatr. 2010;30:271-82.

\section{Intermittent preventive treatment in pregnancy (IPTp)} [http://www.who.int/malaria/areas/preventive_therapies/pregnancy/en/].

7. WHO. World Malaria Report 2019. In CC BY-NC-SA 30 IGO (Organization WH ed. Geneva; 2019.

8. Ribera JM, Hausmann-Muela S, D'Alessandro U, Grietens KP. Malaria in pregnancy: What can the social sciences contribute? Plos Medicine. 2007;4:631-5.

9. Magadi MA, Madise NJ, Rodrigues RN. Frequency and timing of antenatal care in Kenya: explaining the variations between women of different communities. Soc Sci Med. 2000;51:551-61.

10. Ameh S, Owoaje E, Oyo-Ita A, Kabiru CW, Akpet OEO, Etokidem A, Enembe O, Ekpenyong N. Barriers to and determinants of the use of intermittent preventive treatment of malaria in pregnancy in Cross River State, Nigeria: a cross-sectional study. BMC Pregnancy Childbirth. 2016;16:99.

11. Arnaldo P, Cambe MI, Magaco A, Chicumbe S, Rovira-Vallbona E, Rosanas-Urgell A, Enosse SM. Access to and use of preventive intermittent treatment for Malaria during pregnancy: A qualitative study in the Chokwe district, Southern Mozambique. PLoS One. 2019;14:e0203740.

12. Azizi SC, Chongwe G, Chipukuma H, Jacobs C, Zgambo J, Michelo C. Uptake of intermittent preventive treatment for malaria during pregnancy with Sulphadoxine-Pyrimethamine (IPTp-SP) among postpartum women in Zomba District, Malawi: a cross-sectional study. BMC Pregnancy Childbirth. 2018;18:108.

13. Hurley EA, Harvey SA, Rao N, Diarra NH, Klein MC, Diop SI, Doumbia SO. Underreporting and Missed Opportunities for Uptake of Intermittent Preventative Treatment of Malaria in Pregnancy (IPTp) in Mali. PLoS One. 2016;11:e0160008.

14. Rassi C, Graham K, King R, Ssekitooleko J, Mufubenga P, Gudoi SS. Assessing demand-side barriers to uptake of intermittent preventive treatment for malaria in pregnancy: a qualitative study in two regions of Uganda. Malar J. 2016;15:530.

15. Yaya S, Uthman OA, Amouzou A, Bishwajit G. Use of Intermittent Preventive Treatment among Pregnant Women in Sub-Saharan Africa: Evidence from Malaria Indicator Surveys. Trop Med Infect Dis 2018, 3.

16. Scott S, Mens PF, Tinto H, Nahum A, Ruizendaal E, Pagnoni F, Grietens KP, Kendall L, Bojang K, Schallig $\mathrm{H}$, D'Alessandro $\mathrm{U}$. Community-based scheduled screening and treatment of malaria in pregnancy for improved maternal and infant health in The Gambia, Burkina Faso and Benin: study protocol for a randomized controlled trial. Trials. 2014;15:340. 
17. COSMIC Consortium. Community-based Malaria Screening and Treatment for Pregnant Women Receiving Standard Intermittent Preventive Treatment With Sulfadoxine-Pyrimethamine: A Multicenter (The Gambia, Burkina Faso, and Benin) Cluster-randomized Controlled Trial. Clin Infect Dis. 2019;68:586-96.

18. Haines A, Sanders D, Lehmann U, Rowe AK, Lawn JE, Jan S, Walker DG, Bhutta Z. Achieving child survival goals: potential contribution of community health workers. Lancet. 2007;369:2121-31.

19. Lewin S, Munabi-Babigumira S, Glenton C, Daniels K, Bosch-Capblanch X, van Wyk BE, OdgaardJensen J, Johansen M, Aja GN, Zwarenstein M, Scheel IB. Lay health workers in primary and community health care for maternal and child health and the management of infectious diseases. Cochrane Database Syst Rev 2010:CD004015.

20. Schneider $H$, Hlophe $H$, van Rensburg D. Community health workers and the response to HIV/AIDS in South Africa: tensions and prospects. Health Policy Plann. 2008;23:179-87.

21. Singh P, Sachs JD. 1 million community health workers in sub-Saharan Africa by 2015. Lancet. 2013;382:363-5.

22. Mwai GW, Mburu G, Torpey K, Frost P, Ford N, Seeley J. Role and outcomes of community health workers in HIV care in sub-Saharan Africa: a systematic review. J Int AIDS Soc. 2013;16:18586.

23. Matsumoto-Takahashi EL, Kano S. Evaluating active roles of community health workers in accelerating universal access to health services for malaria in Palawan, the Philippines. Trop Med Health. 2016;44:10.

24. Druetz T, Ridde V, Kouanda S, Ly A, Diabate S, Haddad S. Utilization of community health workers for malaria treatment: results from a three-year panel study in the districts of Kaya and Zorgho, Burkina Faso. Malar J. 2015;14:71.

25. Chanda P, Hamainza B, Moonga HB, Chalwe V, Pagnoni F. Community case management of malaria using ACT and RDT in two districts in Zambia: achieving high adherence to test results using community health workers. Malaria Journal 2011, 10.

26. Mubi M, Janson A, Warsame M, Martensson A, Kallander K, Petzold MG, Ngasala B, Maganga G, Gustafsson LL, Massele A, et al: Malaria Rapid Testing by Community Health Workers Is Effective and Safe for Targeting Malaria Treatment: Randomised Cross-Over Trial in Tanzania. Plos One 2011, 6.

27. Chipukuma HM, Zulu JM, Jacobs C, Chongwe G, Chola M, Halwiindi H, Zgambo J, Michelo C. Towards a framework for analyzing determinants of performance of community health workers in malaria prevention and control: a systematic review. Hum Resour Health. 2018;16:22.

28. Davlantes E, Salomao C, Wate F, Sarmento D, Rodrigues H, Halsey ES, Lewis L, Candrinho B, Zulliger R. Malaria case management commodity supply and use by community health workers in Mozambique, 2017. Malar J. 2019;18:47.

29. Dhewantara PW, Ipa M, Widawati M. Individual and contextual factors predicting self-reported malaria among adults in eastern Indonesia: findings from Indonesian community-based survey. Malar J. 2019;18:118. 
30. MacNeill V, Foley M, Quirk A, McCambridge J. Shedding light on research participation effects in behaviour change trials: a qualitative study examining research participant experiences. BMC Public Health. 2016;16:91.

31. Wilding S, Conner M, Prestwich A, Lawton R, Sheeran P. Using the question-behavior effect to change multiple health behaviors: An exploratory randomized controlled trial. J Exp Soc Psychol. 2019;81:53-60.

32. WHO. World Malaria Report 2017. Geneva: World Health Organization; 2017.

33. WHO. World Malaria Report 2018. Licence: CC BY-NC-SA 3.0 IGO.

34. Benin MdISd. Directives nationales de la prise en charge des cas de paludisme 2011.

35. Faso MoHB. Directives nationales pour la prise en charge du paludisme dans les formations sanitaires du Burkina Faso. 2015.

36. Program NMC. The Gambia: Guidelines for the management of malaria. 2010.

37. OANDA. https://www.oanda.com/lang/fr/currency/converter/.

38. Castellani J, Mihaylova B, Ajayi IO, Siribie M, Nsungwa-Sabiiti J, Afonne C, Serme L, Balyeku A, Kabarungi V, Kyaligonza J, et al. Quantifying and Valuing Community Health Worker Time in Improving Access to Malaria Diagnosis and Treatment. Clin Infect Dis. 2016;63:298-305.

39. Brunie A, Wamala-Mucheri P, Otterness C, Akol A, Chen M, Bufumbo L, Weaver M. Keeping community health workers in Uganda motivated: key challenges, facilitators, and preferred program inputs. Glob Health Sci Pract. 2014;2:103-16.

40. Greenspan JAMS, Chebet JJ, Mpunga M, Urassa DP, Winch PJ. Sources of community health worker motivation: a qualitative study in Morogoro Region, Tanzania. Hum Resour Health 2013:11:52.

41. Blanas DANY, Nichols K, Jensen A, Siddiqui A, Hennig N. Barriers to community case management of malaria in Saraya, Senegal: training, and supply-chains. Malar J. 2013;12:95.

42. Braun R, Catalani C, Wimbush J, Israelski D. Community Health Workers and Mobile Technology: A Systematic Review of the Literature. Plos One 2013, 8.

43. Kallander K, Tibenderana JK, Akpogheneta OJ, Strachan DL, Hill Z, ten Asbroek AHA, Conteh L, Kirkwood BR, Meek SR. Mobile Health (mHealth) Approaches and Lessons for Increased Performance and Retention of Community Health Workers in Low- and Middle-Income Countries: A Review. Journal of Medical Internet Research 2013, 15.

44. Kaseje DC, Sempebwa EK, Spencer HC. Malaria chemoprophylaxis to pregnant women provided by community health workers in Saradidi, Kenya. I. Reasons for non-acceptance. Ann Trop Med Parasitol. 1987;81(Suppl 1):77-82.

45. Haver J, Brieger W, Zoungrana J, Ansari N, Kagoma J. Experiences engaging community health workers to provide maternal and newborn health services: implementation of four programs. Int $J$ Gynaecol Obstet. 2015;130(Suppl 2):32-9.

46. Gilmore B, McAuliffe E. Effectiveness of community health workers delivering preventive interventions for maternal and child health in low- and middle-income countries: a systematic review. 
BMC Public Health. 2013;13:847.

47. Okeibunor JC, Orji BC, Brieger W, Ishola G, Otolorin ED, Rawlins B, Ndekhedehe EU, Onyeneho N, Fink G. Preventing malaria in pregnancy through community-directed interventions: evidence from Akwa Ibom State, Nigeria. Malaria Journal 2011, 10.

48. Sunguya BF, Mlunde LB, Ayer R, Jimba M. Towards eliminating malaria in high endemic countries: the roles of community health workers and related cadres and their challenges in integrated community case management for malaria: a systematic review. Malaria Journal 2017, 16.

49. Tani K, Stone A, Exavery A, Njozi M, Baynes CD, Phillips JF, Kante AM. A time-use study of community health worker service activities in three rural districts of Tanzania (Rufiji, Ulanga and Kilombero). BMC Health Serv Res. 2016;16:461.

50. Bratt JH, Foreit J, Chen PL, West C, Janowitz B, De Vargas T. A comparison of four approaches for measuring clinician time use. Health Policy Plann. 1999;14:374-81.

51. Odendaal WA, Lewin S. The provision of TB and HIV/AIDS treatment support by lay health workers in South Africa: a time-and-motion study. Human Resources for Health 2014, 12.

52. Zheng K, Guo MH, Hanauer DA. Using the time and motion method to study clinical work processes and workflow: methodological inconsistencies and a call for standardized research. J Am Med Inform Assoc. 2011;18:704-10.

53. Lopetegui M, Yen P-Y, Lai A, Jeffries J, Embi P, Payne P. Time motion studies in healthcare: What are we talking about? J Biomed Inform. 2014;49:292-9.

54. Boyce MR, Menya D, Turner EL, Laktabai J, Prudhomme-O’Meara W. Evaluation of malaria rapid diagnostic test (RDT) use by community health workers: a longitudinal study in western Kenya. Malaria Journal. 2018;17:206.

55. Ruizendaal E, Schallig H, Scott S, Traore-Coulibaly M, Bradley J, Lompo P, Natama HM, Traore O, Valea I, Dierickx S, et al. Evaluation of Malaria Screening during Pregnancy with Rapid Diagnostic Tests Performed by Community Health Workers in Burkina Faso. Am J Trop Med Hyg. 2017;97:1190-7. 